Original Article

\title{
Same-session and between-day intra-rater reliability of hand-held dynamometer measurements of isometric shoulder extensor strength
}

\author{
Takenori Awatani, MS, RPT ${ }^{1)^{*}}$, Seigo Mori, MS ${ }^{1)}$, Junji Shinohara, PhD ${ }^{1)}$, \\ Hiroya Koshiba, MS ${ }^{2)}$, Miki Nariai, $\mathrm{MS}^{3)}$, Yasutaka Tatsumi, MS ${ }^{1)}$, Akinori Nagata, MS ${ }^{1)}$, \\ IKUHIRo Morikita, $\mathrm{PhD}, \mathrm{MD}^{2,4)}$ \\ 1) Faculty of Sports Science, Kyushu Kyoritsu University: 1-8 Jiyugaoka, Yahatanishi-ku, Kitakyushu, \\ Fukuoka 807-8585, Japan \\ 2) Graduate School of Sport and Exercise Sciences, Osaka University of Health and Sport Sciences, \\ Japan \\ 3) Graduate School of Comprehensive Human Sciences, University of Tsukuba, Japan \\ 4) Faculty of Physical Education, Osaka University of Health and Sport Sciences, Japan
}

\begin{abstract}
Purpose] The purpose of present study was to establish the same-session and between-day intrarater reliability of measurements of extensor strength in the maximum abducted position (MABP) using hand-held dynamometer (HHD). [Subjects] Thirteen healthy volunteers (10 male, 3 female; mean \pm SD: age $19.8 \pm 0.8 \mathrm{y})$ participated in the study. [Methods] Participants in the prone position with maximum abduction of shoulder were instructed to hold the contraction against the ground reaction force, and peak isometric force was recorded using the HHD on the floor. Participants performed maximum isometric contractions lasting $3 \mathrm{~s}$, with 3 trials in one session. Between-day measurements were performed in 2 sessions separated by a 1-week interval. Intra-rater reliability was determined using intraclass correlation coefficients (ICC). Systematic errors were assessed using Bland-Altman analysis for between-day data. [Results] ICC values for same-session data and between-day data were found to be "almost perfect". Systematic errors not existed and only random error existed. [Conclusion] The measurement method used in this study can easily control for experimental conditions and allow precise measurement because the lack of stabilization and the impact of tester strength are removed. Thus, extensor strength in MABP measurement is beneficial for muscle strength assessment.

Key words: Prone, Shoulder abduction, Random error
\end{abstract}

(This article was submitted Oct. 28, 2015, and was accepted Dec. 12, 2015)

\section{INTRODUCTION}

Shoulder muscle strength is often studied with a particular focus on performance in overhead sports, e.g. swimming and tennis. Previous studies ${ }^{1)}$ have investigated the relationships between sports performance and muscle strength, and the reliability of muscle strength measurement. Previous studies investigating the relationships between muscle strength and sports performance have mainly used shoulders in the $90^{\circ}$ flexed position. Previous studies ${ }^{2,3)}$ focusing on the reliability of muscle strength measurement have also tended to focus on the reliability of measuring shoulder extension strength with shoulders in the $90^{\circ}$ flexed position.

\footnotetext{
*Corresponding author. Takenori Awatani (E-mail:awtn9831@gmail.com)

(C)2016 The Society of Physical Therapy Science. Published by IPEC Inc.

This is an open-access article distributed under the terms of the Creative Commons Attribution Non-Commercial No Derivatives (by-nc-nd) License $<$ http://creativecommons.org/licenses/by-nc-nd/4.0/>.
} 
Previous studies ${ }^{1-3)}$ mostly utilized hand-held dynamometers (HHDs). HHDs have low cost and high portability. However, measurement using HHDs is accompanied by technical problems such as a lack of stabilization ${ }^{4}$ and the impact of tester strength $^{5,6)}$, leading to potential measurement errors.

In overhead sports, in particular at front crawl of swimming, the shoulder is moved to extension from the abducted position. Thus, studies utilizing shoulders in the $90^{\circ}$ flexed position do not fully reflect the shoulder movements used in overhead sports. The measurement of extensor strength in the abducted position is important for examining relationships between sports performance and muscle strength. However, the reliability of the measurement of extensor strength in the abducted position using HHD has not been verified.

The purpose of the present study was to establish the same-session and between-day intra-rater reliability of the measurement of extensor strength in the maximum abducted position (MABP) using HHD.

\section{SUBJECTS AND METHODS}

This study was performed with the approval of the Research Ethics Committee of Kyushu Kyoritsu University (Approval No. 2015-04). Participants who were informed both orally and in writing and provided their written consent to participate were included in the study. Thirteen healthy volunteers (10 male, 3 female; mean \pm SD: age $19.8 \pm 0.8 \mathrm{y}$, height $167.7 \pm$ $6.5 \mathrm{~cm}$, body weight $60.8 \pm 5.1 \mathrm{~kg}$ ) participated in the study. Participants had experienced no shoulder pain in the last 6 months and had no history of shoulder surgery. The examiner was a physiotherapist with experience of muscle strength measurement using HHDs.

After warm-up shoulder movements, the trial was started. Muscle strength measurement was performed with a HHD (Mobie MM100C, Minato Medical Science Co., Ltd, Japan). Participants were in the prone position with their toes, abdomen, chest, and mentum touching on the ground. The shoulder to be measured was positioned with maximum abduction with the elbow extended and the forearm in the neutral position. The opposite shoulder was positioned in contact with the side of the body. The HHD was placed on a firm carpet and against the heads of the metacarpal bones on the palm side, and held in place with the hand to prevent any improver movement during measurement. During measurement, the participant was observed by the examiner to maintain proper measurement position. Repeat measurement was made when the position was changed. Peak isometric force was measured on the dominant and non-dominant sides. Participants were instructed to hold the contraction against the ground reaction force, and peak isometric force was recorded using the HHD on the floor. Participants performed maximum isometric contractions lasting $3 \mathrm{~s}$, with 3 trials in one session. Maximum isometric contractions were performed, and a 5-min rest was allowed between trials. Between-day measurements were performed in 2 sessions separated by a 1-week interval. Participants and shoulders were selected randomly using a computer system.

Descriptive data regarding same-session and between-day performance were collected and analyzed. Data were calculated for each measurement, including means and SDs.

Intra-rater reliability was determined using intraclass correlation coefficients $\left(\mathrm{ICC}_{1,1}\right.$ and $\left.\mathrm{ICC}_{1, \mathrm{k}}\right)$ and associated $95 \%$ confidence intervals ( $95 \%$ CIs). ICC values were assessed according to the criteria of Landis et al. 7 ): 0.00 to 0.20 slight; 0.21 to 0.40 fair; 0.41 to 0.60 moderate; 0.61 to 0.80 substantial; and 0.81 to 1.00 almost perfect. Measurement error value was calculated using the standard error of measurement (SEM), the $95 \% \mathrm{CI}$ of the minimal detectable change ( $\left.\mathrm{MDC}_{95}\right)$, and the limits of agreement (LOA). Systematic errors were assessed using Bland-Altman (B-A) analysis ${ }^{8,9)}$ for between-day data. Statistical analysis was performed with R2.8.1, Excel for Windows 2010 (Microsoft Japan Co., Ltd.), and a p value less than 0.05 was considered statistically significant.

$$
\begin{aligned}
& \mathrm{SEM}=\mathrm{SD} * \sqrt{(1-\mathrm{ICC})} \\
& \mathrm{MDC} 95=\mathrm{SEM} * \sqrt{2 * 1.96} \\
& \mathrm{LOA}=\bar{X} \pm 1.96 * \mathrm{SD}
\end{aligned}
$$

\section{RESULTS}

The results of isometric shoulder extensor strength measurement are shown in Table 1. The ICC, SEM, and MDC 95 for same-session data are shown in Table 2. $\mathrm{ICC}_{1,1}$ and $\mathrm{ICC}_{1,3}$ values for same-session data were found to be "almost perfect", $\mathrm{ICC}_{1,3}$ values ranged from 0.862 to 0.981 . The SEM for same-session data was $\leq 5.6 \mathrm{~N}$. The $\mathrm{MDC}_{95}$ for same-session data was $\leq 15.6 \mathrm{~N}$.

The ICC, SEM, and $\mathrm{MDC}_{95}$ for between-day data are shown in Table 3. $\mathrm{ICC}_{1,1}$ and $\mathrm{ICC}_{1,2}$ values for between-day data were found to be "almost perfect", $\mathrm{ICC}_{1,2}$ for the dominant side ranged from 0.812 to 0.985 , and the non-dominant side ranged from 0.797 to 0.984 . The SEM for between-day data was $\leq 6.2 \mathrm{~N}$. The $\mathrm{MDC}_{95}$ for between-day data was $\leq 17.3 \mathrm{~N}$.

The results of B-A analysis are shown in Table 4. Systematic errors not existed and only random error existed. 
Table 1. Isometric shoulder extensor strength with maximum abducted position

\begin{tabular}{llrrrc}
\hline & & Trial 1 & \multicolumn{1}{c}{ Trial 2 } & Trial 3 & Mean of 3 trials \\
\hline \multirow{2}{*}{ Day 1 } & Dominant & $95.5 \pm 31.7$ & $100.2 \pm 33.5$ & $94.2 \pm 37.0$ & $96.6 \pm 30.2$ \\
& Non-dominant & $82.0 \pm 22.5$ & $83.1 \pm 26.5$ & $85.0 \pm 24.2$ & $83.4 \pm 23.8$ \\
\multirow{2}{*}{ Day 2 } & Dominant & $92.8 \pm 25.0$ & $98.9 \pm 25.1$ & $101.5 \pm 25.8$ & $97.8 \pm 24.9$ \\
& Non-dominant & $88.1 \pm 24.1$ & $90.5 \pm 24.2$ & $89.3 \pm 22.7$ & $89.3 \pm 23.1$ \\
\hline
\end{tabular}

Mean \pm SD $(\mathrm{N})$

Participants were in the prone position with shoulder maximum abduction. Participants were instructed to hold the contraction against the ground reaction force, and peak isometric force was recorded using the HHD on the floor. Participants performed maximum isometric contractions lasting $3 \mathrm{~s}$, with 3 trials in one session.

Table 2. Same-session intra-rater reliability

\begin{tabular}{|c|c|c|c|c|c|c|c|c|c|}
\hline & & \multicolumn{4}{|c|}{$\mathrm{ICC}_{1,1}$} & \multicolumn{4}{|c|}{$\mathrm{ICC}_{1,3}$} \\
\hline & & Mean & $95 \% \mathrm{CI}$ & $\begin{array}{c}\text { SEM } \\
(\mathrm{N})\end{array}$ & $\begin{array}{c}\mathrm{MDC}_{95} \\
(\mathrm{~N})\end{array}$ & Mean & $95 \% \mathrm{CI}$ & $\begin{array}{l}\text { SEM } \\
(\mathrm{N})\end{array}$ & $\begin{array}{c}\mathrm{MDC}_{95} \\
(\mathrm{~N})\end{array}$ \\
\hline \multirow{2}{*}{ Day 1} & Dominant & 0.928 & 0.833 to 0.975 & 8.1 & 22.4 & 0.975 & 0.937 to 0.992 & 4.8 & 13.3 \\
\hline & Non-dominant & 0.850 & 0.675 to 0.946 & 9.2 & 25.6 & 0.945 & 0.862 to 0.981 & 5.6 & 15.6 \\
\hline \multirow{2}{*}{ Day 2} & Dominant & 0.879 & 0.730 to 0.957 & 8.7 & 24.0 & 0.956 & 0.890 to 0.985 & 5.2 & 14.5 \\
\hline & Non-dominant & 0.943 & 0.867 to 0.981 & 5.5 & 15.2 & 0.980 & 0.951 to 0.993 & 4.0 & 10.9 \\
\hline
\end{tabular}

ICC: intraclass correlation coefficient; CI: confidence interval; SEM: standard error of measurement; $\mathrm{MDC}_{95}: 95 \%$ confidence interval of minimal detectable change

Table 3. Between-day intra-rater reliability

\begin{tabular}{|c|c|c|c|c|c|c|c|c|}
\hline & \multicolumn{4}{|c|}{$\mathrm{ICC}_{1,1}$} & \multicolumn{4}{|c|}{$\mathrm{ICC}_{1,2}$} \\
\hline & Mean & $95 \% \mathrm{CI}$ & $\begin{array}{c}\text { SEM } \\
(\mathrm{N})\end{array}$ & $\begin{array}{c}\mathrm{MDC}_{95} \\
(\mathrm{~N})\end{array}$ & Mean & $95 \% \mathrm{CI}$ & $\begin{array}{c}\text { SEM } \\
(\mathrm{N})\end{array}$ & $\begin{array}{c}\mathrm{MDC}_{95} \\
(\mathrm{~N})\end{array}$ \\
\hline Dominant & 0.899 & 0.683 to 0.971 & 8.6 & 23.8 & 0.947 & 0.812 to 0.985 & 6.2 & 17.3 \\
\hline Non-dominant & 0.891 & 0.663 to 0.969 & 7.6 & 20.9 & 0.943 & 0.797 to 0.984 & 5.5 & 15.2 \\
\hline
\end{tabular}

ICC: intraclass correlation coefficient; CI: confidence interval; SEM: standard error of measurement; $\mathrm{MDC}_{95}: 95 \%$ confidence interval of minimal detectable change

Table 4. Bland-Altman analysis for between-day

\begin{tabular}{lccccccc}
\hline & $\begin{array}{c}\text { Mean } \\
(\mathrm{N})\end{array}$ & $\begin{array}{c}\text { LOA } \\
(\mathrm{N})\end{array}$ & Regression & $\mathrm{p}$ value & $\begin{array}{c}\text { Proportional } \\
\text { bias }\end{array}$ & $\begin{array}{c}95 \% \mathrm{CI} \\
\text { (N) }\end{array}$ & Fixed bias \\
\hline Dominant & -1.1 & -35.5 to 33.3 & -0.006 & $\mathrm{p}=0.984$ & No & -11.7 to 9.5 & No \\
Non-dominant & -6.0 & -33.7 to 21.8 & 0.344 & $\mathrm{p}=0.250$ & No & -14.5 to 2.6 & No \\
\hline
\end{tabular}

LOA: limits of agreement; CI: confidence interval

\section{DISCUSSION}

The reliability of HHD for assessing shoulder strength has been investigated previously, but the studies have used various shoulder positions. Some studies ${ }^{10,11)}$ have suggested that HHD for assessing shoulder strength is highly reliable. Commonly, isometric shoulder extensor strength is assessed in the seated position with the shoulder in the $0^{\circ}$ flexed and abducted position $^{10)}$, or in the supine position with the shoulder in the $90^{\circ}$ flexed position ${ }^{2,3)}$. Bohannon et al. reported intra-rater reliability $\left(\mathrm{ICC}_{3,1}\right)$ mean values of 0.974 for the dominant side, and 0.973 for the non-dominant side, for supine subjects with the shoulder in the $90^{\circ}$ flexed position. Van den Beld et al. ${ }^{3)}$ reported intra-rater reliability $\left(\mathrm{ICC}_{2,1}\right)$ mean values of 0.95 for the dominant side and 0.93 for the non-dominant side. However, the reliability of extensor strength in MABP measurement in the prone position has not yet been investigated.

In the present study, the test sessions were identical and performed with a 1-week interval. For same-session data, the $\mathrm{ICC}_{1,1}$ was 0.850 (Table 2), indicating "almost perfect" reliability. The $\mathrm{ICC}_{1,3}$ values were $\geq 0.945$, and ranged from 0.862 to 
0.981 (Table 2). Therefore, this measurement method was recommended using the mean of 3 trials. The SEM of the ICC I, $_{3}$ was $\leq 5.6 \mathrm{~N}$. Previous studies ${ }^{3}$ have demonstrated SEM values of $5.3 \mathrm{~N}$ for the dominant side and $6.1 \mathrm{~N}$ for the non-dominant side. Measurement error was also mild in the present study, which was consistent with previous studies.

Between-day reliability was calculated by taking the mean of 3 trials. The $\mathrm{ICC}_{1,1}$ was 0.891 (Table 3 ), suggesting "almost perfect" reliability. The $\mathrm{ICC}_{1,2}$ values were $\geq 0.943$, and ranged from 0.797 to 0.984 (Table 3 ). The results of between-day analysis were also more appropriate when the mean of 3 trials was used. The SEM using $\mathrm{ICC}_{1,2}$ was $\leq 6.2 \mathrm{~N}$. Measurement error was also mild, which was consistent with same-session data.

For B-A analysis, systematic errors were not found, and only random error existed in the dominant and non-dominant sides (Table 4). The $\mathrm{MDC}_{95}$ was $15.6 \mathrm{~N}$ for same-session data and $17.3 \mathrm{~N}$ for between-day data. Therefore, the random error of measurement was $\leq 17.3 \mathrm{~N}$.

Factors affecting the measurement error of HHD are lack of stabilization ${ }^{4}$ and tester strength ${ }^{5,6)}$. In this study, lack of stabilization was excluded from the factors affecting measurement error because HHD measurement was performed on the floor.

Stone et al. ${ }^{6}$ reported that the test-retest data revealed increasing differences between tests as the magnitude of measurement increased, suggesting that our less than satisfactory results were at least in part due to stronger subjects' ability to overcome tester strength. Results of B-A analysis in this study did not reveal any evidence of fixed or proportional bias. The results of the present study did not demonstrate an increasing difference between the tests as the magnitude of measurement increased. In this study, tester strength was excluded from the factors affecting measurement error. The resistive force used was the ground reaction force, which is not related to tester strength. Therefore, with respect to measurement error, inconsistent effort levels in the participants may have had a negative effect on the results.

The present study has several limitations. HHD placement may not have been completely consistent. In addition, occult shoulder problems in patients reporting no history of shoulder issues may have had a negative effect on the reliability of the results.

The measurement method used in this study can control the experimental conditions with ease and allow precise measurement because the lack of stabilization and the impact of tester strength are removed. Thus, extensor strength in MABP measurement is able to assess muscle strength with high intra-rater reliability.

\section{REFERENCES}

1) Gola R, Urbanik C, Iwańska $D$, et al.: Relationship between muscle strength and front crawl swimming velocity. Hum Mov, 2014, 15: 110-115.

2) Bohannon RW: Reference values for extremity muscle strength obtained by hand-held dynamometry from adults aged 20 to 79 years. Arch Phys Med Rehabil, 1997, 78: 26-32. [Medline] [CrossRef]

3) van den Beld WA, van der Sanden GA, Sengers RC, et al.: Validity and reproducibility of hand-held dynamometry in children aged 4-11 years. J Rehabil Med, 2006, 38: 57-64. [Medline] [CrossRef]

4) Kolber M, Cleland J: Strength testing using hand-held dynamometry. Phys Ther Rev, 2005, 10: 99-112. [CrossRef]

5) Wikholm JB, Bohannon RW: Hand-held dynamometer: tester strength makes a difference. J Orthop Sports Phys Ther, 1991, 13: 191-198. [Medline] [CrossRef]

6) Stone CA, Nolan B, Lawlor PG, et al.: Hand-held dynamometry: tester strength is paramount, even in frail populations. J Rehabil Med, 2011, 43: 808-811. [Medline] [CrossRef]

7) Landis JR, Koch GG: The measurement of observer agreement for categorical data. Biometrics, 1977, 33: 159-174. [Medline] [CrossRef]

8) Bland JM, Altman DG: Statistical methods for assessing agreement between two methods of clinical measurement. Lancet, 1986, 1: 307-310. [Medline] [CrossRef]

9) Bland JM, Altman DG: Measuring agreement in method comparison studies. Stat Methods Med Res, 1999, 8: $135-160$. [Medline] [CrossRef]

10) Katoh M: Test-retest reliability of isometric shoulder muscle strength measurement with a handheld dynamometer and belt. J Phys Ther Sci, 2015, 27: 1719-1722. [Medline] [CrossRef]

11) Hirano M, Katoh M: Absolute reliability of shoulder joint horizontal adductor muscle strength measurements using a handheld dynamometer. J Phys Ther Sci, 2015, 27: 2125-2127. [Medline] [CrossRef] 